\title{
PROBLEMATIC ISSUES OF CROSS-CULTURAL INTERACTION IN THE CONTEXT OF INTERNATIONAL MANAGEMENT
}

\author{
Irina V. Onyusheva \\ Etiopia Elisa Changjongpradit
}

Stamford International University, Thailand, Bangkok

This paper discusses the expansion of cross-cultural communication in today's business world along with the cultural structures from two main school of cross-cultural communication. The key aim was providing a clearer view on this problem so that to assist in dealing with cultural differences in work places and in business environment overall. The authors investigated the factors that cause issues in a multicultural workplace and how organization management should approach these matters along with why it is important to have such knowledge and promote cross-cultural communication. Detailed recommendations are also provided on how to minimize communication conflicts in the international business settings.

Keywords: cross-cultural communication; international management; globalization.

\section{Introduction}

In this article we are using "globalization" in many contexts but most frequently it is repeated as a phenomenon promoting trade and foreign companies' participation. Before discussing various roles and manifestations of globalization in the current business context, it is important to consider what exactly does this term mean.

According to Cambridge English Dictionary, two definitions together form the meaning of the word "globalization". These are: "the increase of trade around the world, especially by large companies producing and trading goods in many different countries" and also "a situation in which available goods and services, or social and cultural influences, gradually become similar in all parts of the world". These Cambridge

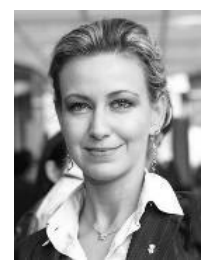

\section{Irina V. Onyusheva}

Stamford International University, Dr., Prof.

Interests - Economics, Strategic Management, Formation, ensuring and increasing economic competitiveness on both micro- and macro- levels; Human Capital development; HR Management; Knowledge Economy; Knowledge Management; Project Management; Management in Education

E-mail: irina.onyusheva@stamford.edu

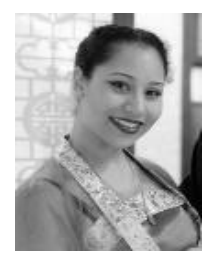

\section{Etiopia Elisa Changjongpradit}

Stamford International University, International MBA Program

Interests - International Business Management, Strategic Management, Global Markets

Email: etiopia.elisa.c@gmail.com 
definitions suggest that globalization involves trading products in different countries and by doing so causing a chain affect which eventually would influence countries worldwide. Another good example which may assist in better understanding of the notion is the BBC article titled "What is Globalization?". It stated that "globalization is the process by which the world is becoming increasingly interconnected as a result of massively increased trade and cultural exchange". The keyword here is "process", in our opinion, it is the key to all other definitions. Therefore, in the framework of this paper we define globalization as "free movement of goods, services and people across the world in a seamless and integrated manner".

The key result from globalization is opening up of the global economy and the codependent increase in trade between nations. In other words, when countries are getting closer to each other through trade and foreign investments, when they open up their economies and go global, the result is the increasing interconnectedness and integration of economies worldwide. But why is globalization still so important to the currently rapidly developing business world?

Globalization also increases opportunities for companies to expand their operations at foreign markets. By accepting foreign investment, a government promotes the development of its infrastructure, in the first place. Foreign companies may also hire local employees, thus increasing the domestic employment level. For example, Thai companies could expand into foreign markets either within the Asian region, or onto more far away nations, thus developing new revenue streams and bring some of that money back into Thailand. This increased capital flow allows for business expansion and increased the overall level of employment. This also encourages government leaders to communicate more about the ways to mutually improve economic conditions and share positive economic results between countries. Openness between governments and industry leaders contributes to shared knowledge and resources. Many industries tend to organize international meetings in which companies share their insights and trends so that that benefit all involved. This can also stimulate domestic competition which, as a result, would create healthier domestic economy leading and strengthen nation's status globally.

Nowadays, the ability to communicate effectively is a truly global challenge. Even when two parties speak the same language, there still might be misunderstandings due to ethnic, religious and other cultural differences. There are extensive research findings available showing how poor communication can lead to poorer performance at the company level. So it is crucial for companies worldwide to understand the impact of globalization on their cross-cultural communication since the latter is part of competitive advantage at the global markets.

This paper focuses on illustrating the problematic issues occurring in the globalized world due to poor cross-cultural communication, another focus is on showing how the related damages from this poor communication could be minimized.

\section{Literature Review}

In this paper we were trying to maintain a clear emphasis on the changes around globalization causing a chain reaction inside organizations and companies that are now dealing with expanding their businesses processes beyond their national border. The key 


\section{THE PROBLEMATIC ISSUES OF CROSS-CULTURAL}

issue with being on a new, different territory or market is dealing with people from somewhat different cultural background, with different values and beliefs.

Relationship management has become one of the most important research topics in public relations of the recent years. Valentini, C. has mentioned that the effect of globalization has accelerated over the last decade with the development of new communications' technologies such as satellite communications and especially the Internet. The quest to find a global framework for public relations continues to attract the interest among both public relations practitioners and researchers. The cultural impact on management is reflected through basic values, attitudes, beliefs and behavior of people. Culture can affect technology transfer, managerial attitudes, managerial ideology and even government-business relationships. Moreover, culture affects how people think and behave. In some societies important decisions are made by a few top managers, while in others, these decisions are diffused throughout enterprises. American society comes under the first case while Japanese companies are the latter case. American and other Western countries' cultural norms require individual rewards which are not typical for Japanese culture. In some societies, risk-taking is encouraged which is not so in others. In Japan people tend to closely identify themselves with their company, mostly because they tend to work for the same companies for decades (if not the whole life). And in America people tend to identify themselves with their narrow occupational group mostly. Some societies encourage cooperation between people. Others encourage competition mostly. Some countries believe in short-term goals, while others are more interested in long-term goals. Western countries put high value on innovation and change, while many other countries prefer stability over change. So, these differences in cultural backgrounds create differences in business environments and behaviors (Kundu, 2001).

The core issue in cross-cultural communication and management is trying to figure out the best way how to work together despite all the differences in cultural background. The necessity for intercultural management becomes imperative under the pressure of globalization, more precisely, under the pressure of the following factors:

a) capital movement,

b) relatively rapid growth observed in developing countries,

c) intensification of trade exchange and,

d) emergence and development of global organizations (Deaconu, A.).

The purpose of this particular paper is to identify what could be potential tools for closing the gaps of miscommunication and mismanagement in the course of ongoing globalization of the business world.

\section{Methodology: Theory}

Regarding the topic explained above there are two approaches to understanding of cross-cultural communication. Both these two approaches/schools assist us in understanding cultural differences in the ways of thinking, behaving and reactions in various situations. Greater understanding of cultures that are different from our own helps finding a common ground, especially in the fields of international management, international organizations' functioning and interaction between international businesses.

The first school or theory is called "Hofstede's Cultural Dimensions". Dutch Professor Dr. Geert Hofstede focused his research on culturally associated behavior and conducted a 
range of comprehensive studies of the national values. His most famous study is titled "Hofstede's six dimension of cultures". According to the methodology presented in this work, each country would have its own score, from 0 to 100 in one of the paired dimensions as follows:

\section{1. $\quad$ Power Distance Index (high vs low).}

This refers to the inequality of people with and without power. Hierarchical distribution of power, how well people "understand their place" in the system. In a society with a low power distance index people tend to believe in equality and that power is spread evenly.

\section{Individualism Vs Collectivism.}

This refers to the strength of ties that people have with other members of their community. High individualism indicates weak interpersonal connections. In this case people are less responsible for other people's actions while in a collectivist society people are supposed to be loyal to a group to which they belong and share the responsibility for its actions/behavior.

3. Masculinity Vs Femininity.

This refers to the distribution of roles between men and women. In the masculine societies, the roles of men and women overlap less, and men are expected to behave assertively. Demonstrating your success, being strong and fast are seen as positive characteristics.

In the feminine societies, however, there is a great deal of overlap between male and female roles, and modesty is perceived as a virtue. Greater importance is placed on good relationships with your direct supervisors, or working with people who cooperate well with one another.

\section{Uncertainty Avoidance Index (high vs low).}

This dimension describe how people can cope with anxiety. People with a high rate of uncertainty avoidance attempt to make life as predictable and controllable as possible. They believe in destiny and that everything is beyond their control as such.

\section{Pragmatic Vs Normative.}

This dimension is also known as long-term vs short-term orientation. Scoring high in pragmatics would means asking the right questions like How and What, using the available data and own reasoning. While normative or scoring low on pragmativity would mean asking mostly the "Why" questions.

\section{6. $\quad$ Indulgence Vs Restraint.}

A country is characterized by a restrained culture, where there is a tendency towards pessimism. People put little emphasis on leisure time and, as the title suggests, they try to restrain themselves in most of life/business situations.

Another well-known school of cross-cultural studies goes back to the teachings of another Dutch professor, Dr. Fons Trompenaars and his work titled "The Seven Dimensions of Culture: understanding and managing cultural differences" which, in its turn, was based on 


\section{THE PROBLEMATIC ISSUES OF CROSS-CULTURAL}

his prior, 1997 book titled "Riding the Waves of Culture". This author also paired the dimensions using the scale to compare as followed:

\section{Universalism vs Particularism.}

Universalism concerns people who believe in standardizing laws and regulations and put them over relationship. These people tend to give out clear instructions, they are strict to processes and spend some on decision-making. The opposite is particularism which means that everything must be considered according to circumstances of a particular situation that drives the decision. Supporters of this sort of thinking would focus on building up relationship and giving more freedom to people in their decision-making. Typical universal nations are the USA, Canada, the UK, the Netherlands, Germany, Scandinavian countries, New Zealand, Australia, and Switzerland, while particularism is very much common in Russian culture, Chinese and also in Latin American.

\section{Individualism vs Communitarianism.}

Individualism is when people believe in personal freedom and achievements and they also believe they can take care of themselves. The opposite group believes that groups are more important than individuals and that group provides more safety and security in exchange for loyalty. Typical individualist cultures include the USA, Canada, the UK, Scandinavia, New Zealand, Australia, and Switzerland, while typical communitarian cultures include the countries of Latin America, Africa and Japan.

\section{Specific vs Diffusion.}

This parameter describes how deeply people tend to get involved. For example, the people from the USA, UK, Switzerland, Germany, Scandinavia, and the Netherlands would mostly keep their work and personal lives separately from each other. Diffusion here means the overlap between work and personal life. People belonging to this second group tend to believe that good relationships are vital in meeting business objectives. Their main goal is to create and build good relationship with each and every individual. Diffusion is mostly peculiar for Asian and Latin-American cultures along with Russian and some of the Southern European cultures such as Spanish, Greek and Italian.

\section{Neutral vs Emotional.}

Representatives of the neutral culture have more tendency to reserve their emotions, neither reveal their thoughts or feelings as opposed to emotional culture in which expressing emotions, thoughts and feelings are always welcome. The representatives of the latter use their emotions to communicate their objectives whereas representatives of the neutral culture would have more like "strict to the point" attitude. Typical neutral cultures include the UK, Sweden, the Netherlands, Finland, and Germany while typical emotional cultures include Italy, France, Spain, and the countries of Latin America.

\section{Achievement vs Ascription.}

The parameter is focused on how people view status. Achievers are the people who are performance-oriented and believe that "you are what you do". These are the values are found mostly in Western cultures. For supporters of ascription believe that one should be valued for 
who they are. Power, title, job position and family status matter in these cultures, spread mostly in Asia and particularly in the Middle East.

6. $\quad$ Sequential Time vs Synchronous Time.

This parameter deals directly with how people manage time. The popular concept of "Time is money" is valued by sequential timers who are very punctual and would work with just one project so that to meet the deadline. As opposed to that, synchronous times would see the past, the present, and the future as interwoven periods. They often work on several projects at the same time, and they also tend to view plans and commitments in a very flexible manner. Typical sequential-time cultures include Germany, the UK, and the US as opposed to synchronous-time cultures - Japan, Argentina and Mexico.

\section{7. $\quad$ Internal Direction versus Outer Direction.}

This parameter describes how people are related to their environment. There are people who believe they can control the nature in general or their environment in particular for the achievement of their goals. This includes how they work with teams and within organizations. This style of behavior (and management) is typical for the Anglo-Saxon cultures. While the outer direction of thought is commonly found in Asian culture and in Russia. These people believe that the nature (or their environment) controls them; thus, they must work with their environment to achieve the needed goals.

Both schools (approaches) mentioned above can be used as models for better understanding of people from different cultural backgrounds so that to minimize and prevent misunderstandings and thus enjoy better working relationship. This is especially useful for the cases when people from around the world find themselves in a situation of doing business together and when managing a diverse group of people/employees are thus required.

\section{Research Findings}

The mentality of "I'm right" and "You're wrong"is only able to escalate differences and generate more conflict which may go as far as manifestations of racism and extremism. Unfortunately, this is commonly found, in both intentional and unintentional manifestations, in societies overall, and most importantly for our case - in the international business setting. Looking at communication as the process of coding and decoding messages, it is obvious that there are many points in this complex process where communication may easily break down. Successful communication largely depends on the shared culture. When having communication between people of different cultures, even if they are using the same language for communication, things can go wrong. Knowledge of a language does not automatically give you the background knowledge that native speakers assume the other side shares with them. The main issue here is that there will be nearly always a dominating group or an individual that will try to enforce their culture as the superior one. This attitude does not only harm the harmony of the workflow but might potentially lead to much bigger risks and even damages to organization's image, reputation and consequently - to the profit level. 


\section{THE PROBLEMATIC ISSUES OF CROSS-CULTURAL}

\section{Discussion}

The key element in understanding cross-cultural communication and all the issues related to this notion would be linking back to what culture really is and what it represents along with the roles it plays in the context of business and international management.

Culture is determined by the ways people think, speak, perceive, and behave. Culture assumes the shared understanding of meanings and it is the core of society stability. In other words, culture is used to describe the behaviors that represent the general operating norms in a particular social environment. Culture also explains how members behave towards each other and with other groups.

First, culture is relative which means culture is neither right, nor wrong but rather a gray area full of beliefs, religion and customs. This also logically leads us to the conclusion that culture is not absolute. People of different nationalities simply perceive the world in a different way and manner. Each culture has its own view of what is acceptable and not. Second, culture is not about individual but it is more about group behavior and community. It refers to a collectiveness of shared values, beliefs and background. Third, culture is in a way inherited from generations to generations, it is being passed from older to younger. However, it can also be derived from the social environment. For example, due to differences between the past and the present states of a particular environment, adaptability and changes could be applied and found, so they should also be expected in the future as well. In other words, "culture" can be learned and in some cases it can be adapted. The fact is people from different countries have different ways of conducting their daily lives. Anthropologists view culture as a biological evolution and the main means of humans' adaptation to the world. Therefore, culture covers spiritual, material, intellectual, and emotional features of society or of a certain social group. It also includes arts and literature, lifestyle, ways of living, values, traditions, and beliefs.

The study of cross-culture communication is essential for business in order to understand how individuals think and process information and also what influences how they project and receive information. This could be applied in the business context of "organizational culture" in which behavior and attitudes of both employees and executives form parts of the organization's mission and vision.

As it was already mentioned at the very beginning, the contemporary business world has already reached such level of connectedness at which everyone is influenced and driven by one another. Businesses are spreading beyond their national borders with the purpose to expand their market share and reach higher profitability along with more sustainable business aims. Since such business expansion basically means entering a different market or environment, adaptability becomes an important to different languages and different culture overall. It is crucial for organization's management to prevent any sort of potential conflict and to maintain strong organizational core values, which may be, inter aplia, through applying the theoretical achievement of the both schools of cross-cultural communication (Hofstede and Trompenaars). In this case management would be able to minimize the causes of potential conflicts and therefore to create a harmonious working atmosphere which, in its turn, will enhance the organizational workflow. Below we present our own recommendations which might be useful for the management placed in the business context of a different country. 


\section{Recommendations}

The key to effective cross-cultural communication is knowledge. Firstly, it is essential that people understand the potential problems caused by damaged cross-cultural communication and thus make conscious efforts to overcome these problems. The key here is very much internal factor - be open-minded and understanding with others. Secondly, it is important to assume that one's effort will not always be successful and with that in mind, to find efforts to adjust one's behavior appropriately. At the early stage of its development already the organization should have an idea or a plan on how to learn and understand not only the market and the consumer needs at it but also the local cultural aspects, the way of life, why people react or behave the way they do etc. Organizations who are sending expatriates as managers (and this has already become a popular method of management) have to organize proper preparation and knowledge for these managers. The headquarters needs to ensure proper support for the overseas management so that to the organization's success and minimize challenges from both internal and external forces. Understanding the work in a multinational atmosphere is always challenging but this is the challenge that can be overcome with proper mutual understanding, respect and harmony.

\section{Conclusion}

Cross-cultural challenges in the international business context have become a keenly followed topic in the last two decades. By now, there are already enough examples of business failures or stagnation of joint ventures due to management's inability to recognize cross-cultural challenges and tackle them appropriately. There are also the examples of companies that managed to provide sufficient trainings and other cultural management activities for their employees sent abroad as or hired from other countries. Such activities ensured that the cross-cultural challenges have been tackled effectively. The world is becoming smaller day by day, therefore, managers involved in international businesses activities should become more sensitive to the challenges emanating from the cultural and ethnic landscape of the countries they are working in.

\section{References:}

Deaconu, A. Globalization And Change Management. http://www.academia.edu/22797633/Globalization_and_Change_Management, Accessed 22 Sept. 2017.

GCSE Bitesize, (2017). What is globalisation? (n.d.). Retrieved September 02, 2017, from http://www.bbc.co.uk/schools/gcsebitesize/geography/globalisation/globalisation_rev1.shtml

Globalization Meaning in the Cambridge English Dictionary. (n.d.). Retrieved September 02, 2017, from http://dictionary.cambridge.org/dictionary/english/globalization

Hofstede's Cultural Dimensions: Understanding Different Countries. (n.d.). Retrieved September 23, 2017, from https://www.mindtools.com/pages/article/newLDR_66.htm

Kawar, T. I. (2012). Cross-Cultural Differences in Management. International Journal of Business and Social Science, March issue, Accessed 22 Sept. 2017.

Kundu, S. C. (2001). Managing Cross-Cultural Diversity A Challenge For Present And Future Organizations. Delhi Business Review, 2, 8 p., Accessed 22 Sept. 2017. 


\section{THE PROBLEMATIC ISSUES OF CROSS-CULTURAL}

Majlergaard, D. (2017). The top 5 challenges managers of cultural diverse teams are facing. Gugin, Gugin Publishing, 25 Apr. 2017, gugin.com/the-top-5-challenges-managers-of-culturaldiverse-teams-are-facing/. Accessed 23 Sept. 2017.

Meyer, E. (2017). Being the Boss in Brussels, Boston, and Beijing. Harvard Business Review, July 2017, Accessed 22 Sept. 2017.

Pearce, R. (2006). Globalisation and development: an international business strategy approach. Transnational Corporations, 15 (1). pp. 39-74. Accessed 22 Sept. 2017.

Singh, D. (2017). Managing Cross-Cultural Diversity: Issues and Challenges in Global Organizations. IOSR Journal of Mechanical and Civil Engineering, pp. 43-50.

Stening, B. W. (1979). Problems in Cross-Culture Contact. www.researchgate.net/publication/256404410_Problems_in_Cross-

Cultural_Contact_A_Literature_Review. Accessed 23 Sept. 2017.

The Seven Dimensions of Culture: Understanding and Managing Cultural Differences. (n.d.). Retrieved September 23, 2017, from https://www.mindtools.com/pages/article/sevendimensions.htm

Valentini, C. (n.d.). Global versus cultural approaches in public relationship management: The case of the European Union. Retrieved September 22, 2017, from http:// www.emeraldinsight.com/1363-254X.htm

Zhou, C. (n.d.). Literature Review and analysis on the Cross-Culture Awareness in English Translation of Chinese Scenic Spot Introductions. Retrieved September 22, 2017, from http://www.celtjournal.co.uk

Paper submitted

Paper accepted for publishing

Paper published online
26 January 2018

14 March 2018

15 June 2018 